\title{
Endoscopic and Clinical Factors Affecting the Prognosis of Colorectal Endoscopic Submucosal Dissection-Related Perforation
}

Dong-Uk Kang, Yunsik Choi, Ho-Su Lee, Hyo Jeong Lee, Sang Hyoung Park, Dong-Hoon Yang, Soon Man Yoon, Kyung-Jo Kim, Byong Duk Ye, Seung-Jae Myung, Suk-Kyun Yang, Jin-Ho Kim, and Jeong-Sik Byeon

Department of Gastroenterology, Asan Medical Center, University of Ulsan College of Medicine, Seoul, Korea

Background/Aims: Although colorectal endoscopic submucosal dissection (ESD)-related perforation is not uncommon, the factors affecting clinical outcomes after perforation have not been investigated. This study was designed to investigate the factors influencing the clinical course of ESD-related coIon perforation. Methods: Forty-three patients with colorectal ESD-related perforation were evaluated. The perforations were classified as endoscopic or radiologic perforations. The patients' medical records and endoscopic pictures were analyzed. Results: The clinical outcomes were assessed by the duration of nil per os, intravenous antibiotics administration, and hospital stays, which were $2.7 \pm 1.5,4.9 \pm 2.3$, and $5.1 \pm 2.3$ days, respectively. Multivariate analyses revealed that a larger tumor size, ESD failure, specific endoscopists, and abdominal pain were independently related to a poorer outcome. The time between perforation and clipping was $15.8 \pm 25.4$ minutes in the endoscopic perforation group. The multivariate analysis of this group indicated that delayed clipping, specific endoscopists, and abdominal pain were independently associated with poorer outcomes. Conclusions: Tumor size, ESD failure, abdominal pain, and the endoscopist were factors that affected the clinical outcomes of patients with colorectal ESD-related perforation. The time between the perforation and clipping was an additional factor influencing the clinical course of endoscopic perforation. Decreasing this time period may improve outcomes. (Gut Liver 2016;10:420-428)

Key Words: Colon; Endoscopic submucosal dissection; Outcome; Perforation

\section{INTRODUCTION}

Endoscopic submucosal dissection (ESD) has emerged as a standard treatment for early gastric cancer. ${ }^{1}$ Through technical improvements and the development of various devices, many centers now also try to perform ESD in the colorectum. ${ }^{2,3}$ However, when ESD is applied to colorectal tumors, the risk of complications, particularly perforation, is high because the colon wall is thinner than the gastric wall. ${ }^{4}$ The reported perforation rates range from $1.4 \%$ to $10.4 \% .^{2,5-7}$ Although surgical intervention is not necessary in most ESD-related perforation cases, it is advisable to avoid colorectal ESD-related perforation because it may prolong hospital stay with antibiotic use and nil per os (NPO).

Several studies have reported that the risk factors for colorectal ESD-related perforation were a large tumor size, presence of fibrosis, and a laterally spreading tumor type. ${ }^{4,6,8}$ The preventive factor for perforation was submucosal injection with hyaluronic acid. ${ }^{4}$ To improve the clinical outcome after colorectal ESD, we need to take measures to prevent perforation by paying more attention to cases with the aforementioned risk factors. In addition, it is necessary to understand the factors that affect the clinical course of perforation and to modify these factors to improve the postperforation course, if feasible. However, few studies have investigated the factors associated with outcomes of colorectal ESD-related perforation. ${ }^{8,9}$ Accordingly, this study aimed to investigate the factors affecting the clinical course of ESD-related colon perforation.

\section{MATERIALS AND METHODS}

\section{Patients}

From September 2007 to February 2013, 608 patients under-

Correspondence to: Jeong-Sik Byeon

Department of Gastroenterology, Asan Medical Center, 88 Olympic-ro 43-gil, Songpa-gu, Seoul 05505, Korea

Tel: +82-2-3010-3905, Fax: +82-2-476-0824, E-mail: jsbyeon@amc.seoul.kr

Received on June 8, 2015. Revised on July 14, 2015. Accepted on July 30, 2015. Published online January 19, 2016 pISSN 1976-2283 eISSN 2005-1212 http://dx.doi.org/10.5009/gnl15252

@ This is an Open Access article distributed under the terms of the Creative Commons Attribution Non-Commercial License (http://creativecommons.org/licenses/by-nc/4.0) which permits unrestricted non-commercial use, distribution, and reproduction in any medium, provided the original work is properly cited. 
went colorectal ESD in our center. Of these, 45 patients (7.4\%) experienced ESD-related colon perforation. Their clinical data were obtained by reviewing medical records and colonoscopy pictures. In four of the 45 patients, ESD failed and complete tumor removal was impossible. Of these four patients with ESD failure, two were excluded because they underwent elective surgery for the purpose of residual tumor resection before complete improvement of perforation-related clinical status. Thus, 43 patients were finally enrolled in this study (Fig. 1).

The macroscopic appearance of the tumors was classified as polypoid, nonpolypoid, or laterally spreading tumor. Accord- ing to the Paris classification, a polypoid lesion included 0-Is and 0-Ip lesions. Nonpolypoid lesions included 0-IIa, 0-IIb, and 0-IIc, and combined lesions such as 0-IIa+IIc and 0-IIc+IIa. A laterally spreading tumor was defined as a slightly elevated, nonprotruding lesion $>20 \mathrm{~mm}$ in diameter. ${ }^{10}$ Tumor locations were divided into right colon (cecum, ascending, and transverse colon), left colon (descending and sigmoid colon), upper rectum (between $12 \mathrm{~cm}$ and $16 \mathrm{~cm}$ from the anal verge), and middle to lower rectum (distal to $12 \mathrm{~cm}$ from the anal verge). ${ }^{11,12}$ Histological assessment was made according to the World Health Organization classification of gastrointestinal epithelial neopla-
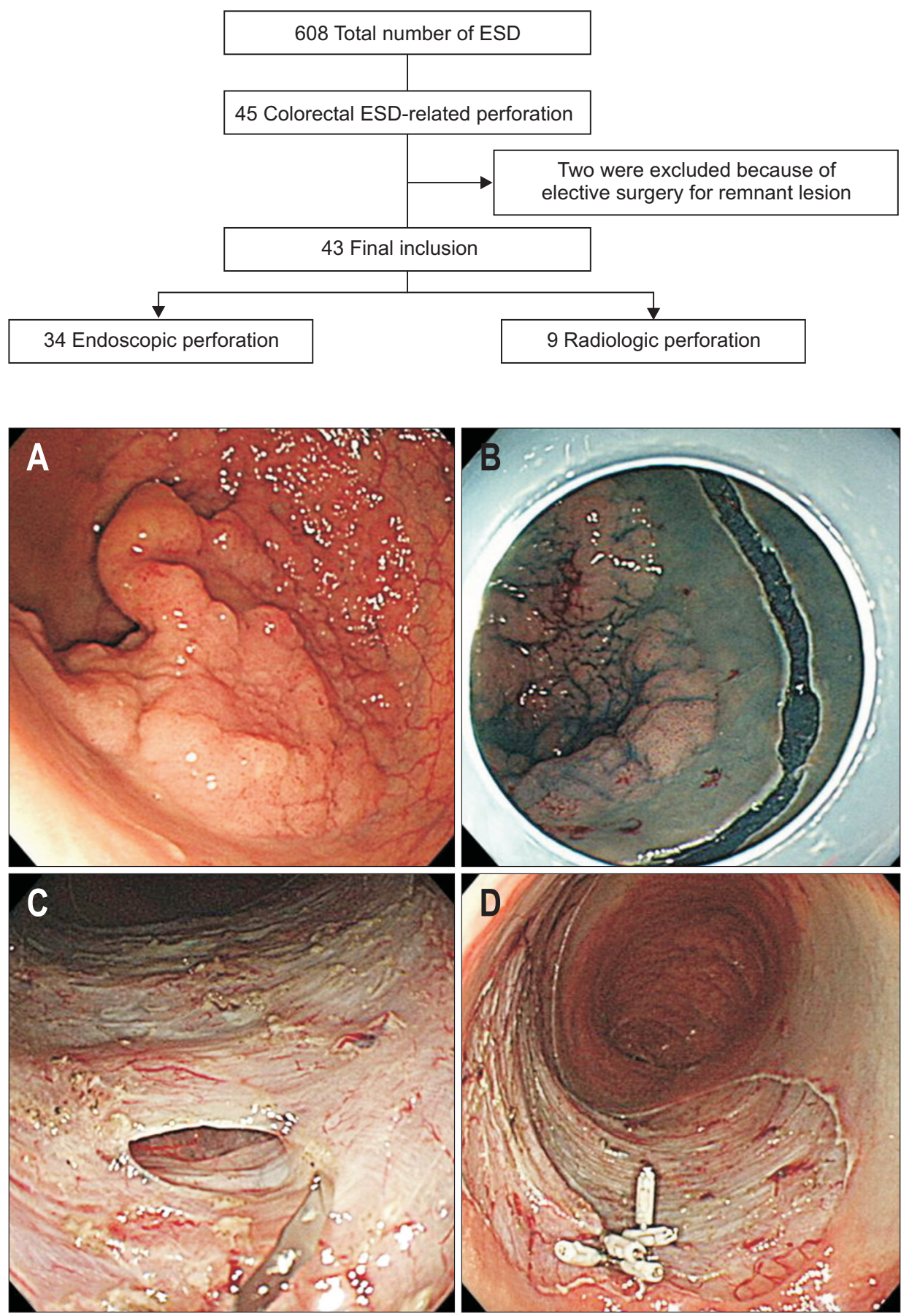

Fig. 1. Selection of patients with colorectal endoscopic submucosal dissection (ESD)-related perforation.
Fig. 2. Endoscopic perforation. (A) Laterally spreading tumor measuring approximately 4 to $5 \mathrm{~cm}$ in size. (B) Mucosal cutting performed for endoscopic submucosal dissection. (C) Small endoscopic perforation. (D) Endoscopic clipping performed to close the perforation. 
sia. ${ }^{13}$ This study was approved by the Institutional Review Board of Asan Medical Center (IRB number: 2014-0125).

\section{ESD procedures}

The ESD procedures were performed by five endoscopists (D.H.Y., S.M.Y., K.J.K., B.D.Y., and J.S.B.) who are highly experienced in therapeutic colonoscopy procedures. Bowel preparation status was classified as excellent, good, fair, or poor. ${ }^{14}$ Room air was used for inflation of the colon. ESD time was defined as the time from the submucosal injection to complete resection of the lesion. ESD method was classified into two groups: ESD with snaring and ESD only. ESD with snaring comprised an initial submucosal dissection and final snaring; this procedure is detailed in our previous report. ${ }^{15}$ The selection of ESD method depended on the endoscopist's own decision or preference. Complete en bloc resection was defined as a lesion that was removed in a single piece with tumor-free lateral and vertical margins. Perforation type was categorized as endoscopic or radiologic perforation. Endoscopic perforation was defined as a gross colorectal wall defect noted during the ESD procedure (Fig. 2). Radiologic perforation was defined as a perforation identified by the presence of pneumoperitoneum and/or pneumoretroperitoneum on a simple abdominal X-ray and/or computed tomography (CT) scan after ESD without signs of a colorectal wall defect during the ESD procedure (Fig. 3). ${ }^{16}$ All patients underwent chest and abdominal X-ray immediately after the ESD.

\section{Management of perforation}

In the case of endoscopic perforation, endoscopic closure of the perforation site was attempted using endoscopic clipping during the ESD. Intravenous antibiotics were administered and patients were NPO until the absence of or improvement in clinically significant peritonitis symptoms/signs and laboratory abnormalities. The radiologic perforation group was treated largely by the same measures as the endoscopic perforation group except that there was no application of clips during the ESD.

In the endoscopic perforation group, we investigated the time between perforation and clipping, which was defined as the time from detection of perforation to completion of appropriate clipping. The time between perforation and antibiotics was also investigated, which was defined as the time from detection of perforation to injection of the first antibiotics.

\section{Clinical outcome variables and risk factors}

Clinical outcome variables consisted of the duration of NPO, duration of intravenous antibiotics, and duration of hospital
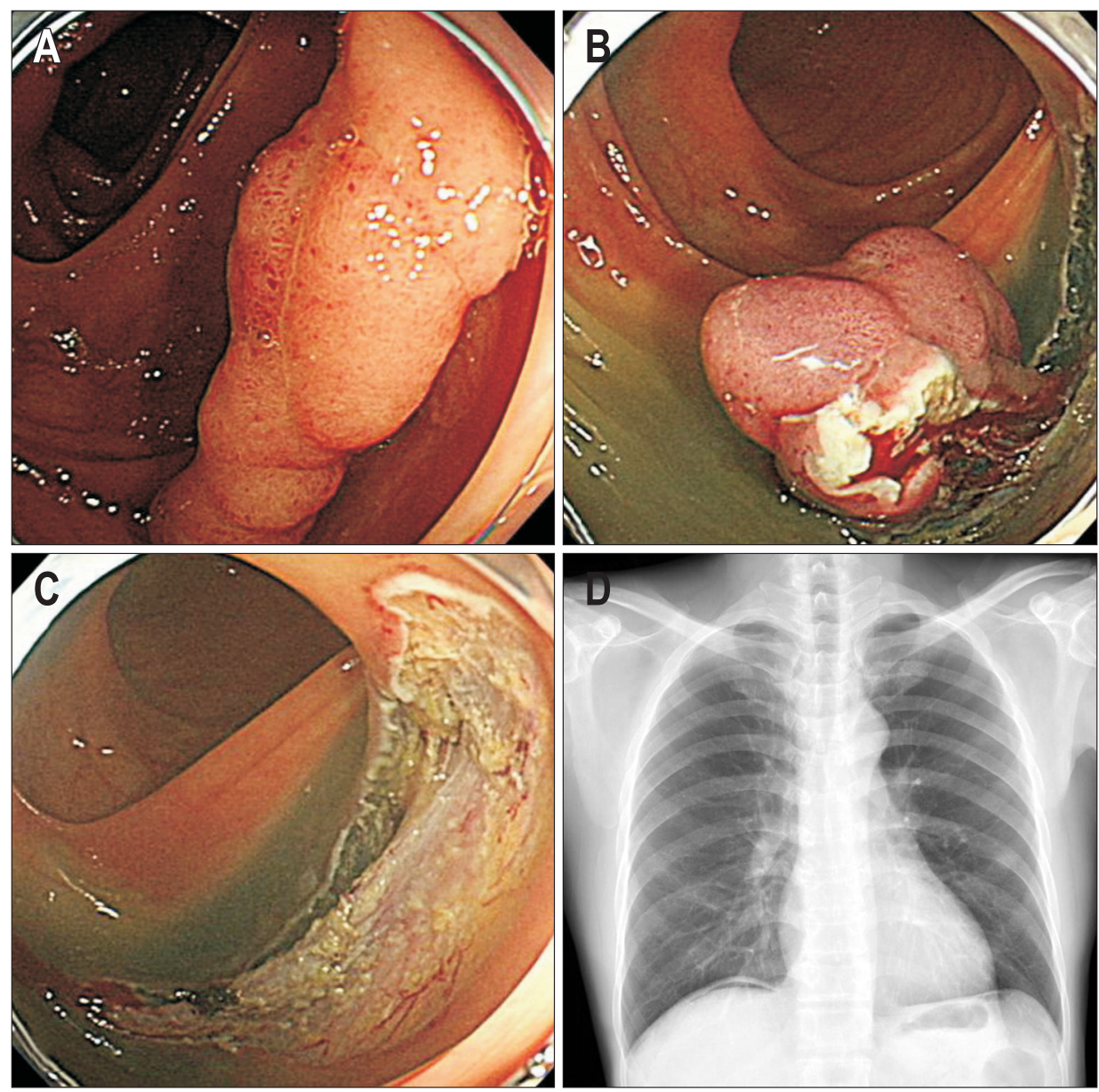

Fig. 3. Radiologic perforation. (A) Laterally spreading tumor measuring approximately $3 \mathrm{~cm}$ in size. (B) Endoscopic submucosal dissection (ESD) procedure. (C) Definitive evidence of endoscopic perforation was not observed on the post-ESD ulcer. (D) Small amount of free air noted just below the diaphragm, which implies radiologic perforation without any evidence of endoscopic perforation. 
stay. We investigated possible risk factors that could affect the clinical course after ESD-related perforation. Risk factors were classified into four categories: (1) patient characteristics; (2) tumor characteristics; (3) ESD procedure-related factors; and (4) post-ESD clinical findings. Patient characteristics included age and sex. Tumor characteristics comprised the macroscopic appearance, location, size, and pathology of the tumor. ESD procedure-related factors were the bowel preparation, ESD time, ESD method, en bloc resection, perforation type, the endoscopist, and ESD success. Post-ESD clinical findings included abdominal pain, fever, free air on radiographic examination, leukocyte count, and C-reactive protein (CRP) level. In the endoscopic perforation group, the time between perforation and clipping and the time between perforation and antibiotics were further investigated as possible risk factors.

\section{Statistical analysis}

Associations between possible risk factors and clinical outcome variables were analyzed with a linear regression model followed by a multivariable linear regression model with a stepwise selection method. When categorical variables were ana-

Table 1. Baseline Characteristics of Patients and Tumors

\begin{tabular}{|c|c|}
\hline Characteristic & Value $(n=43)$ \\
\hline \multicolumn{2}{|l|}{ Patient demographics } \\
\hline Age, yr & $64.0 \pm 10.8$ \\
\hline Sex, male:female & $27: 16$ \\
\hline \multicolumn{2}{|l|}{ Tumor characteristics } \\
\hline \multicolumn{2}{|l|}{ Macroscopic appearance } \\
\hline Polypoid & 9 \\
\hline Nonpolypoid & 4 \\
\hline Laterally spreading tumor & 30 \\
\hline \multicolumn{2}{|l|}{ Tumor location } \\
\hline Right colon* & 20 \\
\hline Left colon $^{\dagger}$ & 9 \\
\hline Upper rectum $^{\ddagger}$ & 3 \\
\hline Middle to lower rectum $\$$ & 11 \\
\hline Tumor size, mm & $33.5 \pm 19.4$ \\
\hline \multicolumn{2}{|l|}{ Pathology } \\
\hline Low-grade dysplasia & 12 \\
\hline High-grade dysplasia & 17 \\
\hline Carcinoma & 12 \\
\hline Carcinoid & 2 \\
\hline
\end{tabular}

Data are presented as mean \pm SD or number.

*Right colon is composed of the cecum, ascending, and transverse colon; ${ }^{\dagger}$ Left colon is composed of the descending and sigmoid colon; ${ }^{\ddagger}$ Upper rectum was defined between $12 \mathrm{~cm}$ and $16 \mathrm{~cm}$ from the anal verge; ${ }^{\S}$ Middle to lower rectum was defined distal to $12 \mathrm{~cm}$ from the anal verge.
Table 2. Features Related to the ESD Procedure and Clinical Findings after ESD

\begin{tabular}{|c|c|}
\hline Variable & Value $(n=43)$ \\
\hline \multicolumn{2}{|l|}{ Features related to ESD procedure } \\
\hline \multicolumn{2}{|l|}{ Bowel preparation } \\
\hline Excellent & 7 \\
\hline Good & 33 \\
\hline Fair & 3 \\
\hline Poor & 0 \\
\hline ESD time, min & $96.6 \pm 91.5$ \\
\hline \multicolumn{2}{|l|}{ Resection method } \\
\hline ESD with snaring & 14 \\
\hline ESD only & 29 \\
\hline \multicolumn{2}{|l|}{ En bloc resection } \\
\hline No & 12 \\
\hline Yes & 31 \\
\hline Perforation size, $\mathrm{mm}^{*}$ & $2.4 \pm 1.8$ \\
\hline \multicolumn{2}{|l|}{ Perforation type } \\
\hline Endoscopic perforation & 34 \\
\hline Radiologic perforation & 9 \\
\hline \multicolumn{2}{|l|}{ Endoscopist } \\
\hline A & 15 \\
\hline B & 20 \\
\hline $\mathrm{C}$ & 6 \\
\hline $\mathrm{D}$ & 1 \\
\hline E & 1 \\
\hline \multicolumn{2}{|l|}{ Success of ESD } \\
\hline Success & 41 \\
\hline Failure & 2 \\
\hline \multicolumn{2}{|l|}{ Clinical findings after ESD } \\
\hline \multicolumn{2}{|l|}{ Abdominal pain } \\
\hline Absent & 22 \\
\hline Present & 21 \\
\hline \multicolumn{2}{|l|}{ Fever $^{\dagger}$} \\
\hline Absent & 41 \\
\hline Present & 2 \\
\hline \multicolumn{2}{|l|}{ Free air } \\
\hline Absent & 13 \\
\hline Present & 30 \\
\hline Leukocyte counts, $\times 10^{3} / \mu \mathrm{L}^{\ddagger}$ & $10.0 \pm 3.7$ \\
\hline $\mathrm{CRP}, \mathrm{mg} / \mathrm{dL}^{\S}$ & $4.8 \pm 5.3$ \\
\hline
\end{tabular}

Data are presented as mean \pm SD or number.

ESD, endoscopic submucosal dissection; CRP, C-reactive protein.

*Perforation size was only measured for cases of endoscopic perforation; ${ }^{\dagger}$ Fever was defined as an axillary body temperature higher than $37.2^{\circ} \mathrm{C}$ within 1 day of perforation; ${ }^{\ddagger}$ Leukocyte count data were missing for five patients; ${ }^{\S} \mathrm{CRP}$ level data were missing for seven patients. 
lyzed, dummy variables were used. All reported p-values were two sided and a p-value less than 0.05 was considered statistically significant. Statistical analyses were performed by using SPSS version 20.0 (IBM Corp., Armonk, NY, USA).

\section{RESULTS}

\section{Baseline characteristics of patients and tumors}

The baseline characteristics of the patients and tumors are summarized in Table 1. There were 27 males (63\%) and the mean ( \pm standard deviation [SD]) age of the patients was $64.0 \pm 10.8$ years. The mean tumor size was $33.5 \pm 19.4 \mathrm{~mm}$. The most common macroscopic appearance of the lesions was the laterally spreading tumor (30/43). The right colon was the most frequent location of perforation (20/43). High-grade dysplasia was the most common pathology (17/43), followed by carcinoma (12/43), low-grade dysplasia (12/43), and carcinoid (2/43).

\section{Features related to ESD procedure and clinical findings after ESD}

The mean ESD time was $96.6 \pm 91.5$ minutes. En bloc resection was not achieved in 12 of 43 patients (27.9\%). There were 34 cases $(79.1 \%)$ of endoscopic perforation. The mean size of endoscopic perforation was $2.4 \pm 1.8 \mathrm{~mm}$. ESD failed and the tumor was not completely resected in two cases. There was no patient who underwent surgery because of colon perforation although two patients underwent surgeries to remove remnant tumors without the purpose of correction of bowel perforation. The mean leukocyte count after ESD was $10.0 \pm 3.7 \times 10^{3} / \mu \mathrm{L}$. The mean CRP level was $4.8 \pm 5.3 \mathrm{mg} / \mathrm{dL}$. Free air was present in 30 patients (69.8\%). ESD procedure-related factors and post-ESD clinical findings are summarized in Table 2.

\section{Clinical outcomes and analyses for factors affecting the outcomes in all patients}

The mean duration of NPO was $2.7 \pm 1.5$ days. The mean duration of intravenous antibiotics was $4.9 \pm 2.3$ days. The mean hospital stay was $5.1 \pm 2.3$ days. On univariate analysis, NPO duration was prolonged with radiologic perforation, endoscopists B and C, ESD failure, and the presence of abdominal pain. A longer duration of intravenous antibiotic use was associated with a larger tumor size, endoscopist C, presence of abdominal pain, presence of free air, and a higher CRP level. A prolonged hospital stay was related with a larger tumor size, endoscopist $\mathrm{C}$, presence of abdominal pain, presence of free air, and a higher CRP level (Table 3). Endoscopic perforation size and the quality

Table 3. Univariate Linear Regression Analysis of the Factors Related to ESD Perforation Outcomes for all ESD Perforation Cases*

\begin{tabular}{|c|c|c|c|c|c|c|c|c|c|}
\hline & \multicolumn{3}{|c|}{ Duration of NPO } & \multicolumn{3}{|c|}{ Duration of intravenous antibiotics ${ }^{\dagger}$} & \multicolumn{3}{|c|}{ Duration of hospital stay $^{\dagger}$} \\
\hline & $\beta$ & $95 \% \mathrm{CI}$ & p-value & $\beta$ & $95 \% \mathrm{CI}$ & p-value & $\beta$ & $95 \% \mathrm{CI}$ & p-value \\
\hline Tumor size & 0.008 & -0.017 to 0.032 & 0.531 & 0.052 & 0.017 to 0.087 & 0.005 & 0.054 & 0.020 to 0.089 & 0.003 \\
\hline \multicolumn{10}{|l|}{ Perforation type } \\
\hline Endoscopic & Ref & & & Ref & & & Ref & & \\
\hline Radiologic & 1.196 & 0.122 to 2.270 & 0.030 & 0.790 & -1.042 to 2.623 & 0.388 & 1.004 & -0.809 to 2.817 & 0.269 \\
\hline \multicolumn{10}{|l|}{ Endoscopist $^{\ddagger}$} \\
\hline A & Ref & & & Ref & & & Ref & & \\
\hline $\mathrm{B}$ & 1.150 & 0.229 to 2.071 & 0.016 & -0.231 & -1.701 to 1.238 & 0.751 & -0.071 & -1.541 to 1.400 & 0.923 \\
\hline $\mathrm{C}$ & 2.200 & 0.898 to 3.502 & 0.002 & 3.333 & 1.192 to 5.475 & 0.003 & 3.400 & 1.257 to 5.543 & 0.003 \\
\hline \multicolumn{10}{|l|}{ Success of ESD } \\
\hline Failure & 2.390 & 0.325 to 4.455 & 0.024 & 1.158 & -3.555 to 5.871 & 0.622 & 0.947 & -3.752 to 5.646 & 0.685 \\
\hline \multicolumn{10}{|l|}{ Abdominal pain } \\
\hline Absent & Ref & & & Ref & & & Ref & & \\
\hline Present & 0.918 & 0.038 to 1.798 & 0.041 & 1.825 & 0.455 to 3.196 & 0.010 & 2.000 & 0.664 to 3.336 & 0.004 \\
\hline \multicolumn{10}{|l|}{ Free air } \\
\hline Absent & Ref & & & Ref & & & Ref & & \\
\hline Present & 0.813 & -0.162 to 1.788 & 0.100 & 1.721 & 0.162 to 3.280 & 0.031 & 2.006 & 0.493 to 3.520 & 0.011 \\
\hline CRP & 0.071 & -0.027 to 0.168 & 0.150 & 0.227 & 0.092 to 0.362 & 0.002 & 0.236 & 0.105 to 0.368 & 0.001 \\
\hline
\end{tabular}

ESD, endoscopic submucosal dissection; NPO, nil per os; $\beta$, coefficient; CI, confidence interval; Ref, reference; CRP, C-reactive protein.

${ }^{*}$ Only the $p<0.05$ factors are shown in this table; ${ }^{\dagger}$ For four patients, the data related to the intravenous antibiotic administration and hospital stay durations were not included in this analysis because in these cases, the antibiotic durations and hospital stays were prolonged because of various conditions, such as surgery, and comorbid infections, such as osteomyelitis, irrespective of the patients' perforation-related status; ${ }^{\ddagger}$ Because only one case was performed by each endoscopist, endoscopists D and E were excluded from this analysis. 
of preparation were not associated with any clinical outcomes in univariate analysis. On multivariate analysis, abdominal pain, ESD failure, and specific endoscopistst were independent risk factors that influenced the duration of NPO. Tumor size and the endoscopist were factors affecting the duration of intravenous antibiotics. Hospital stay was influenced by tumor size, the endoscopist, and abdominal pain (Table 4).

\section{Subgroup analysis: factors affecting the clinical out- comes in endoscopic perforation}

Factors affecting clinical outcomes of endoscopic perforation were analyzed separately in the endoscopic perforation group. The mean time between perforation and clipping was $15.7 \pm 25.4$ minutes. The mean time between perforation and antibiotics was
$141.5 \pm 170.5$ minutes. On univariate linear regression analysis, NPO duration was prolonged with a time between perforation and clipping $>10$ minutes, endoscopists B and C, and abdomina pain. A longer duration of intravenous antibiotics use was associated with endoscopist $\mathrm{C}$ and abdominal pain. A prolonged hospital stay was related with endoscopist $\mathrm{C}$ and abdomina pain (Table 5). The time between perforation and antibiotics was not related with clinical outcome. On multivariate analysis, a time between perforation and clipping $>10$ minutes, endoscopist $\mathrm{C}$, and abdominal pain were independent risk factors that influenced the duration of NPO. Endoscopist $\mathrm{C}$ and abdominal pain were factors affecting the duration of intravenous antibiotics. Hospital stay was influenced by endoscopist $\mathrm{C}$ and abdominal pain (Table 6).

Table 4. Multivariate Linear Regression Analysis for Factors Related to ESD Perforation Outcome in all ESD Perforation Cases*

\begin{tabular}{|c|c|c|c|c|c|c|c|c|c|}
\hline & \multicolumn{3}{|c|}{ Duration of NPO } & \multicolumn{3}{|c|}{ Duration of intravenous antibiotics } & \multicolumn{3}{|c|}{ Duration of hospital stay } \\
\hline & $\beta$ & $95 \% \mathrm{CI}$ & p-value & $\beta$ & $95 \% \mathrm{CI}$ & p-value & $\beta$ & $95 \% \mathrm{CI}$ & p-value \\
\hline Tumor size & - & - & - & 0.045 & 0.012 to 0.077 & 0.009 & 0.047 & 0.016 to 0.078 & 0.004 \\
\hline \multicolumn{10}{|l|}{ Endoscopist } \\
\hline A & Ref & & & Ref & & & Ref & & \\
\hline B & 0.748 & 0.005 to 1.491 & 0.049 & 0.032 & -1.323 to 1.387 & 0.962 & 0.204 & -1.096 to 1.504 & 0.751 \\
\hline C & 1.919 & 0.877 to 2.960 & 0.001 & 3.056 & 1.192 to 4.921 & 0.002 & 3.097 & 1.309 to 4.885 & 0.001 \\
\hline \multicolumn{10}{|c|}{ Success of ESD } \\
\hline Success & Ref & & & & & & & & \\
\hline Failure & 4.874 & 2.661 to 7.088 & $<0.001$ & - & - & - & - & - & - \\
\hline \multicolumn{10}{|c|}{ Abdominal pain } \\
\hline Absent & Ref & & & Ref & & & Ref & & \\
\hline Present & 1.055 & 0.369 to 1.724 & 0.004 & 1.234 & -0.041 to 2.509 & 0.057 & 1.334 & 0.111 to 2.557 & 0.033 \\
\hline
\end{tabular}

ESD, endoscopic submucosal dissection; NPO, nil per os; $\beta$ : coefficient; CI, confidence interval; Ref, reference.

${ }^{*}$ Only the $\mathrm{p}<0.05$ factors are shown in this table.

Table 5. Univariate Linear Regression Analysis for the Factors Related to ESD Perforation Outcome in Endoscopic Perforation Cases*

\begin{tabular}{|c|c|c|c|c|c|c|c|c|c|}
\hline & \multicolumn{3}{|c|}{ Duration of NPO } & \multicolumn{3}{|c|}{ Duration of intravenous antibiotics } & \multicolumn{3}{|c|}{ Duration of hospital stay } \\
\hline & $\beta$ & $95 \% \mathrm{CI}$ & p-value & $\beta$ & $95 \% \mathrm{CI}$ & p-value & $\beta$ & 95\% CI & p-value \\
\hline \multirow{2}{*}{\multicolumn{10}{|c|}{$\begin{array}{l}\text { Time between perforation } \\
\text { and clipping, } \min ^{\dagger}\end{array}$}} \\
\hline & & & & & & & & & \\
\hline$<10$ & Ref & & & Ref & & & Ref & & \\
\hline$\geq 10$ & 1.244 & 0.308 to 2.181 & 0.011 & 0.884 & -0.638 to 2.406 & 0.244 & 0.973 & -0.555 to 2.501 & 0.203 \\
\hline \multicolumn{10}{|l|}{ Endoscopist } \\
\hline A & Ref & & & Ref & & & Ref & & \\
\hline B & 1.045 & 0.201 to 1.889 & 0.017 & 0.500 & -0.524 to 1.524 & 0.326 & 0.571 & -0.512 to 1.655 & 0.289 \\
\hline $\mathrm{C}$ & 2.857 & 1.549 to 4.165 & $<0.001$ & 5.738 & 4.014 to 7.463 & $<0.001$ & 5.595 & 3.772 to 7.419 & $<0.001$ \\
\hline \multicolumn{10}{|c|}{ Abdominal pain } \\
\hline Absent & Ref & & & Ref & & & Ref & & \\
\hline Present & 1.294 & 0.401 to 2.187 & 0.006 & 2.206 & 0.870 to 3.542 & 0.002 & 2.370 & 1.067 to 3.673 & 0.001 \\
\hline
\end{tabular}

ESD, endoscopic submucosal dissection; NPO, nil per os; $\beta$, coefficient; CI, confidence interval; Ref, reference.

*Only the $p<0.05$ factors are shown in this table; ${ }^{\dagger}$ For one patient, the data for the time between perforation and clipping were not included in this analysis because the endoscopic picture was absent. 
Table 6. Multivariate Linear Regression Analysis for Factors Related to ESD Perforation Outcome in Endoscopic Perforation Cases*

\begin{tabular}{|c|c|c|c|c|c|c|c|c|c|}
\hline & \multicolumn{3}{|c|}{ Duration of NPO } & \multicolumn{3}{|c|}{ Duration of intravenous antibiotics } & \multicolumn{3}{|c|}{ Duration of hospital stay } \\
\hline & $\beta$ & $95 \% \mathrm{CI}$ & p-value & $\beta$ & $95 \% \mathrm{CI}$ & p-value & $\beta$ & $95 \% \mathrm{CI}$ & p-value \\
\hline \multirow{2}{*}{\multicolumn{10}{|c|}{$\begin{array}{l}\text { Time between perforation } \\
\text { and clipping, min }\end{array}$}} \\
\hline & & & & & & & & & \\
\hline$<10$ & Ref & & & & & & & & \\
\hline$\geq 10$ & 0.942 & 0.073 to 1.811 & 0.035 & - & - & - & - & - & - \\
\hline \multicolumn{10}{|c|}{ Endoscopist } \\
\hline A & Ref & & & Ref & & & Ref & & \\
\hline B & 0.319 & -0.550 to 1.188 & 0.458 & 0.122 & -0.835 to 1.080 & 0.795 & 0.133 & -0.848 to 1.115 & 0.783 \\
\hline C & 2.947 & 1.695 to 4.198 & $<0.001$ & 4.888 & 3.226 to 6.550 & $<0.001$ & 4.610 & 2.906 to 6.313 & $<0.001$ \\
\hline \multicolumn{10}{|c|}{ Abdominal pain } \\
\hline Absent & Ref & & & Ref & & & Ref & & \\
\hline Present & 0.747 & 0.025 to 1.468 & 0.043 & 1.332 & 0.365 to 2.280 & 0.009 & 1.533 & 0.552 to 2.515 & 0.003 \\
\hline
\end{tabular}

ESD, endoscopic submucosal dissection; NPO, nil per os; $\beta$, coefficient; CI, confidence interval; Ref, reference.

${ }^{*}$ Only the $\mathrm{p}<0.05$ factors are shown in this table.

\section{DISCUSSION}

In our present comprehensive analysis, we investigated factors affecting clinical outcomes after colorectal ESD-related perforation. Clinical outcomes were assessed in terms of the durations of NPO, intravenous antibiotics, and hospital stay. Tumor size, ESD failure, the endoscopist, and abdominal pain were factors that influenced the postperforation clinical outcome. In addition, as the time of clipping was delayed after perforation, the duration of NPO was prolonged in the endoscopic perforation group. These findings are important because we can predict the clinical course after colorectal ESD-related perforation based on these factors, through which we can be more alert to patients who may have a poorer prognosis. Furthermore, we can improve the postperforation clinical course by shortening the time between perforation and clipping in the endoscopic perforation group. Although previous studies mentioned young age, abdominal pain, and radiologic perforation as factors affecting duration of NPO or duration of hospital stay, their suggestions were inconclusive because of statistical insignificance or absence of multivariate analysis. ${ }^{8,9}$

Tumor size and ESD failure may be related to the technical difficulty of ESD. The former is a known risk factor for ESDrelated colon perforation, ${ }^{8}$ which indirectly implies technical difficulty. Because it takes a long time to manipulate a scope or knife for technically difficult cases, the amount of insufflated air could increase. This delay may result in a large amount of air leakage with or without fecal spillage if perforation occurs, which may lead to longer durations of NPO and intravenous antibiotics. This hypothesis can be supported by a previous study showing that large pneumoperitoneums were associated with the need for early surgical treatment within 24 hours after endoscopic clipping for iatrogenic colon perforation. ${ }^{17}$ However, further studies are necessary to clearly understand how tumor size and ESD failure affect clinical outcome because the presence of free air had a statistically insignificant effect on outcome in the multivariate analysis of our study.

Abdominal pain is the consequence of a distended abdomen caused by air leakage through the perforation site and/or peritonitis caused by fecal spillage into the abdominal cavity. Both a distended abdomen and peritonitis may make it difficult to resume normal oral intake, which extends the NPO duration. A long duration of antibiotics is also needed to control peritonitis. The endoscopist was a consistent risk factor influencing all clinical outcome variables. It is well-known that management and prognosis vary according to the physician in charge in various medical fields, such as cardiology, rheumatology, and gastroenterology. ${ }^{18-22}$ Endoscopists' skill, knowledge, and experience may affect their decision regarding when to resume oral intake and how long to continue the duration of NPO and hospital stay. We believe that endoscopist education may help standardize the management of colorectal ESD-related perforation.

The middle to lower rectum is partially or wholly located in the extraperitoneal cavity, and we can assume that perforation outcomes in this area would be better than that of the upper rectal or proximal colonic perforation because of a lower risk of peritonitis. However, the present study did not show any relationship between tumor location and postperforation clinical outcome. Although the reason for this finding is unclear, we suggest that intraperitoneal perforation might have occurred in some cases with middle to lower rectal perforation, which could not be identified in our study because CT scans were not performed in all cases with middle to lower rectal perforations. The absence of a prognostic difference may have also been attributed to good clinical outcomes in upper rectal or proximal colonic perforation cases because of qualified medical care, including 
clipping and appropriate antibiotic use.

In the subgroup analysis of the postperforation clinical course in the endoscopic perforation group, the time between perforation and clipping influenced the duration of NPO. If perforation closure by endoscopic clipping is delayed, the amount of air leakage and fecal spillage may increase. This may lead to severe peritonitis and poorer clinical outcome. The time between perforation and clipping is an important factor when managing patients with colorectal ESD-related perforation because this is a modifiable factor, which means that we can improve the clinical course by managing this factor properly. Based on our study, it is apparently reasonable that closure of perforation by endoscopic clipping should be performed as quickly as possible for a better outcome. However, there is a concern that dissection may be difficult if clipping is performed before the submucosal dissection is completed because the applied clips may interfere with surgical knife manipulation. Therefore, we recommend a prompt endoscopic clipping just after submucosal dissection has proceeded to a location where knife motion would not be affected by clipping. We recommend an immediate clipping once endoscopic perforation is noticed if the location of clipping does not interrupt the submucosal dissection.

This study has some limitations. First, clinical outcome indicators in this study were not objective ones. Objective indices such as surgery and mortality could not be used in this study because there was no case of surgery and mortality. Instead, NPO duration, which was used in this study, may be affected not only by the patient's medical condition but also by the individual endoscopist's strategy. However, we performed multivariate analysis including endoscopists to adjust maximally subjective characteristics of these outcomes. Therefore we suggest these indices could be used as clinical outcome parameters although they are not perfect. Furthermore, we assessed other objective parameters such as free air, fever, leukocyte count and CRP level, because of the retrospective design of our study. Nonetheless, we could not yet investigate some physical examination-related data, such as rebound tenderness and bowel sounds, which are possible factors that could influence the postperforation clinical course. Thus, we still need prospective investigations. Second, although this is one of the largest series of colorectal ESD-related perforations, the number of cases was still small. Nonetheless, we believe that our study is meaningful because this is the first study to comprehensively analyze factors affecting the clinical outcome of colorectal ESD-related perforation and because we were able to find a modifiable factor through which the clinical course can be improved.

In conclusion, tumor size, ESD failure, the endoscopist, and abdominal pain were factors affecting the clinical outcome of colorectal ESD-related perforation. The time between perforation and clipping was a manageable factor influencing the postperforation clinical course. Decreasing this time may help to improve outcomes.

\section{CONFLICTS OF INTEREST}

No potential conflict of interest relevant to this article was reported.

\section{REFERENCES}

1. Isomoto H, Shikuwa S, Yamaguchi N, et al. Endoscopic submucosal dissection for early gastric cancer: a large-scale feasibility study. Gut 2009;58:331-336.

2. Tanaka S, Oka S, Kaneko I, et al. Endoscopic submucosal dissection for colorectal neoplasia: possibility of standardization. Gastrointest Endosc 2007;66:100-107.

3. Tanaka S, Tamegai Y, Tsuda S, Saito Y, Yahagi N, Yamano HO. Multicenter questionnaire survey on the current situation of colorectal endoscopic submucosal dissection in Japan. Dig Endosc 2010;22 Suppl 1:S2-S8.

4. Lee EJ, Lee JB, Choi YS, et al. Clinical risk factors for perforation during endoscopic submucosal dissection (ESD) for large-sized, nonpedunculated colorectal tumors. Surg Endosc 2012;26:15871594.

5. Tamegai Y, Saito Y, Masaki N, et al. Endoscopic submucosal dissection: a safe technique for colorectal tumors. Endoscopy 2007; 39:418-422.

6. Isomoto $\mathrm{H}$, Nishiyama $\mathrm{H}$, Yamaguchi $\mathrm{N}$, et al. Clinicopathological factors associated with clinical outcomes of endoscopic submucosal dissection for colorectal epithelial neoplasms. Endoscopy 2009 41:679-683.

7. Yoshida N, Yagi N, Naito Y, Yoshikawa T. Safe procedure in endoscopic submucosal dissection for colorectal tumors focused on preventing complications. World J Gastroenterol 2010;16:16881695.

8. Kim ES, Cho KB, Park KS, et al. Factors predictive of perforation during endoscopic submucosal dissection for the treatment of colorectal tumors. Endoscopy 2011;43:573-578.

9. Yoon JY, Kim JH, Lee JY, et al. Clinical outcomes for patients with perforations during endoscopic submucosal dissection of laterally spreading tumors of the colorectum. Surg Endosc 2013;27:487493.

10. Endoscopic Classification Review Group. Update on the Paris classification of superficial neoplastic lesions in the digestive tract. Endoscopy 2005;37:570-578.

11. Japanese Research Society for Cancer of the Colon and Rectum. General rules for clinical and pathological studies on cancer of the colon, rectum and anus. Part 1: clinical classification. Jpn J Surg 1983;13:557-573.

12. Goligher JC, Duthie HL, Dedombal FT, Watts JM. Abdomino-anal pull-through excision for tumors of the mid-third of the rectum: a comparison with low anterior resection. Br J Surg 1965;52:323334.

13. Hamilton SR, Aaltonen LA; International Agency for Research on Cancer; World Health Organization. Pathology and genetics of 
tumours of the digestive system. Lyon: IARC Press, 2000.

14. Aronchick CA, Lipshutz WH, Wright SH, DuFrayne F, Bergman G. Validation of an instrument to assess colon cleansing. Am J Gastroenterol 1999;94:2667.

15. Byeon JS, Yang DH, Kim KJ, et al. Endoscopic submucosal dissection with or without snaring for colorectal neoplasms. Gastrointest Endosc 2011;74:1075-1083.

16. Yang DH, Byeon JS, Lee $\mathrm{KH}$, et al. Is endoscopic closure with clips effective for both diagnostic and therapeutic colonoscopyassociated bowel perforation? Surg Endosc 2010;24:1177-1185.

17. Cho SB, Lee WS, Joo YE, et al. Therapeutic options for iatrogenic colon perforation: feasibility of endoscopic clip closure and predictors of the need for early surgery. Surg Endosc 2012;26:473479.

18. Suraci C, Mulas F, Rossi MC, Gentile S, Giorda CB. Management of newly diagnosed patients with type 2 diabetes: what are the attitudes of physicians? A SUBITO!AMD survey on the early diabetes treatment in Italy. Acta Diabetol 2012;49:429-433.

19. Ward MM, Leigh JP, Fries JF. Progression of functional disability in patients with rheumatoid arthritis: associations with rheumatology subspecialty care. Arch Intern Med 1993;153:2229-2237.

20. Ayanian JZ, Hauptman PJ, Guadagnoli E, Antman EM, Pashos CL, McNeil BJ. Knowledge and practices of generalist and specialist physicians regarding drug therapy for acute myocardial infarction. N Engl J Med 1994;331:1136-1142.

21. Provenzale D, Ofman J, Gralnek I, Rabeneck L, Koff R, McCrory D. Gastroenterologist specialist care and care provided by generalists: an evaluation of effectiveness and efficiency. Am J Gastroenterol 2003;98:21-28.

22. Lee SP, Sung IK, Kim JH, Lee SY, Park HS, Shim CS. Risk factors for incomplete polyp resection during colonoscopic polypectomy. Gut Liver 2015;9:66-72. 